\title{
SEMIÓTICA, HISTORIA Y FICCIÓN EN TERRA NOSTRA
}

\author{
Por \\ ZUNILDA GERTEL. \\ University of Wisconsin
}

El discurso narrativo de Terra Nostra implica una conciencia crítica de la función de la historia en la realidad presente hispanoamericana. No se retorna a la historia para juzgarla, interpretarla o reconstruirla, sino para recuperarla como acervo cultural del presente. En este sentido la novela es culminación de la obra de Fuentes y, a la vez, texto crucial de la narrativa hispanoamericana de la década del 70.

Mi propósito en este ensayo es mostrar que la función semiótica de la historia como integrad ora de la ficción permite al facto histórico desprenderse del eje de su continuidad diacrónica y, en su nueva condición de signo móvil, proyectarse como discontinuidad hasta integrarse (metonimizarse) en el contexto espacial del presente. Esta espacialización de la temporalidad histórica, es decir, esta validez de contemporaneidad que tiene intrínsecamente el hecho histórico, confiere a la narrativa la capacidad de producir y desarrollar un discurso cultural como apertura que marca una notoria evolución en el lenguaje y en la epistemología del discurso de la novela hispanoamericana.

Para que se comprenda más claramente mi propuesta, creo conveniente hacer unas consideraciones preliminares con respecto a la situación de Hispanoamérica, nacida ante el mundo occidental del siglo XVI, entre el conflicto de dos culturas: la indígena y la hispana. El error trágico de la conquista - error sin expiación catártica-fue, sin duda, la violación y el rechazo del orden ancestral y natural de América. Esta falta histórica, que deviene falta mítica, implica una perdida original y cultural que se transfiere en epistema de ruptura. La conquista establece en la realidad hispanoamericana un orden epistemológico unívoco, que se manifiesta específicamente como orden de lo mismo--el pensamiento lógico occidental--, frente al mund o de lo otro-la realidad indígena, cuyo sistema de pensamiento abarca la a mbigüedad de lo diferente-. La cultura indígena, ante la imposición del conquistador, no tiene otra alternativa que asimilarse a lo unívoco o destruirse. Surge así un vacío histórico-cultural que se encubre en la 
inestabilidad de dos fuerzas recurrentes: represión y violencia. Como dice Octavio Paz "en la historia de la conquista la libertad que se equivoca se llama herejía". Y es el lenguaje de la conquista española el que traduce este sistema de pensamiento estatuido, modelo ejemplar que responde a un centro fijo. "Las palabras significan lo que contienen y contienen lo que significan"; jerarquía verbal que no reconoce la diferencia ni la transformación. La literatura se presenta como arte producido, según un determinado canon de realidad y estética que, con pocas excepciones, ha de perdurar hasta principios del siglo XX. Si bien ya en el siglo XIX las corrientes del pensamiento romántico y modernista emprenden la indagación de esa falta original de la cultura americana, habrá que llegar al siglo XX, y más especificamente a las décadas del 60 y 70 , para que los escritores, en especial los novelistas, se planteen como conciencia crítica la problemática de ese vacío cultural.

La narrativa de la década del 60 orienta su reclamo al mundo mítico y, primordialmente, a su aspecto irracional-fantástico. Rayuela (1963), Cien años de soledad (1967), El obsceno pájaro de la noche (1970), ejemplifican la búsqueda de la contradictoria realidad hispanoamericana que ha de nacer de las raíces de esa ausencia. Para que surgiera esta nueva novela fue necesario el descubrimiento de un nuevo lenguaje que se situara en el no-lugar del mito, allí donde no hay límites entre verdadero y falso, y donde la palabra creadora puede instalarse como unidad de diferencias. Sin embargo, desde la perspectiva de los últimos diez años se puede ya decir que la década del 70 marca una nueva actitud del discurso narrativo. El reclamo para saldar la falta original inquiere a la historia y más particularmente a la crónica, como artefactos, textos pre-existentes que re-encarnan y actuán en el contexto del presente. El lenguaje mítico parece ser insuficiente. ${ }^{1}$ La coexistencia verdadero-falso, es superada por la apertura finito-infinito. Concierto barroco (1974), Yo el Supremo (1974), y como texto crucial, Terra Nostra (1975), ${ }^{2}$ son ejemplos significativos de esta evolución de la novela hacia un discurso cultural, de sentido post-mítico.

Para comprender a Terra Nostra es preciso ubicarla en este proceso operacional de la narrativa. Así se entenderá que la fragmentaria acumulación de escrituras es su defecto y también su virtud, ya que esta superposición de textos opera activamente como cobertura que enmascara el vacío y a la vez lo

\footnotetext{
1 Llamo discurso mítico al discurso cuyo lenguaje diferencial se desvía de la convención dicotómica lógico-ilógico; racional-irracional; verdadero-falso, para situarse en un no-lugar, vértice de la contradicción como coexistencia. El discurso mítico rechaza la unicidad y ha de ser funcionalmente, por lo menos, bisémico, o polisémico.

${ }^{2}$ Como referencia de las citas textuales de la novela indicaré las páginas correspondientes a la primera edición: Terra Nostra (México: Joaquín Mortiz, 1975).
} 
denuncia. Todo acercamiento a Terra Nostra tendrá que partir de la base de que esta novela es un verdadero quiasmo de lectura y escritura, o mejor, la escritura como apoteosis de la lectura. Texto generado de otros textos (leídos), memoria de un pasado que se re-escribe y que posteriormente volverá a ser otra diferente forma de lectura. Como dice Borges "una literatura difiere de otra ulterior o anterior, menos por el tex to que por la manera de ser leída: si me fuera otorgado leer cualquier página actual-ésta por ejemplo-como la leerán el año dos mil, yo sabría cómo será la literatura del año dos mil". ${ }^{3}$ Pero si todo libro es por naturaleza re-escritura como experiencia de una metalectura, en el caso singular de Terra Nostra dicha interrelación actúa como una poética semiótica e implica una estructura ex-céntrica cuyos elementos funcionales-sean palabras, secuencias, fragmentos de textos---son signos móviles creadores de su propio espacio en abierta disyunción. Sin embargo, este aparente caos tiene su coherencia intrínseca y su unidad en el principio semiótico de la validez. Cada signo vale y funciona según su relación con los otros.

Terra Nostra emerge así como una novela cuya escritura marca una singular configuración del discurso y del espacio narrativo. La identidad de los narradores se enmascara en un proteico yo-tú-él [nosotros] que encubre y descubre la ausencia de toda individualidad. Narradores y personajes aparecen, cambian y reaparecen transformados en las tres partes de la novela, "El viejo mundo", "El mundo nuevo" y "El otro mundo". Felipe, el protagonista de "El viejo mundo" encarna el histórico Felipe II, como signo del supremo poder y ambición de España, y también de su decadencia y caída. Felipe es en la novela una figura proteica, como una ficticia simbiosis de los Habsburgos y los Austrias perpetuados en la inmovilidad de su absolutismo. En un pasaje narrativo Felipe se sueña a sí mismo como si fuera tres hombres diferentes "los tres un solo hombre aunque dueño de tres rostros distintos, propios de tres distintos tiempos: los tres siempre capturados en este valle pétreo y sin puerta, o sin más que el cielo" (p. 145).

El discurso narrativo muestra esta dispersión del sujeto que, paradójicamente, más se acentúa, cuando el personaje más busca afirmar su yo univoco. Uno de los momentos en que es más evidente esta contradicción es cuando Felipe, ascendiend o las gradas del Escorial, ante los fantasmas de su terror tiene la revelación de la impotencia de su poder: "- - No quiero que el mundo cambie. No quiero que mi cuerpo muera, se desintegre, se transforme y renazca en forma animal... Quiero que el mundo se detenga y libere mi cuerpo resurrecto en la eternidad del Paraíso, al lado de Dios"(p. 161). Esta secuencia que aparece en la primera parte de la novela y que cronológicamente

\footnotetext{
${ }^{3}$ Otras inquisiciones (Buenos Aires: Emecé, 1960), p. 218.
} 
se corresponde con la fecha histórica del reinado de Felipe, se re-escribe en el texto de "El otro mundo" en el tiempo futuro de 1999. Felipe reaparece subiendo las gradas de El Escorial que, de pronto, se transfieren en el descenso al Valle de los Caídos:

[Felipe] Levantó un pie y lo posó sobre el primer peldaño de la escalera. . Cerró los ojos para no verse esta vez, como la otra, a sí mismo, sino al mundo... Abrió los ojos. Había ascendid o por los treinta y tres peldaños de su capilla. El sol dañó su mirada. Un valle bravo y recio se abría ante ella...

— ¿Dónde estoy... por favor... dónde?, logró murmurar Felipe.

- Hombre, en el Valle de los Caídos.

- ¿Qué? ¿Cuáles caídos?

- Caramba, los caídos por España, el monumento de Santa Cruz...

- ¿Qué día es éste?

- Como saber el día, pues eso sí quién sabe. Ahora que el año sí que lo sé, que es el de mil nueve noventa y nueve. ¿El señor nunca ha visitado el Valle de los Caídos...?

Felipe miró la inmensa cruz de piedra: -No, nunca lo he visitado. Es que hace más de cuatrocientos años que me fui. (pp. 760-763)

La presencia atemporal de Felipe, como signo reiterado en la tercera parte del libro, reinstala un contexto histórico: El Escorial, en otro futuro con respecto a éste: El Valle de los Caidos, que a su vez es también pasado con respecto al discurso de la novela. Es así como dos significantes distintos, temporal y espacialmente, se superponen como un mismo lenguaje históricocultural cuyo significado marca el absolutismo en su permanencia arqueológica. Significativamente la institución, el hecho histórico, genera un espacio cultural como ideología establecida.

Esta traslación de signos se re-crea en la metamorfosis de personajes que son como trazos en espejos que muestran el reverso de otras caras borradas y re-escritas a distintos niveles del texto. En Terra Nostra las figuras históricas coexisten con las invenciones del arte y la literatura, especialmente las del mundo hispano-renacentista que marcan una ideología diferencial en ruptura con la realidad unívoca de "los mismos", como Don Quijote, Don Juan y La Celestina. Son estas figuras hechos culturales, tan históricos como los fijados por la historiografía. Don Quijote, como signo proteico, se confunde con Don Juan y también se identifica con Cervantes, quien reaparece al final del libro como cronista que ha registrado los hechos del relato. Celestina es una transfigura mediadora que sostiene todas las metamorfosis de la novela: niña, mujer, deidad azteca, virgen cristiana, rostro de los labios tatuados, máscara de plumas, demonio, bruja, señora de las mariposas. Celestina, el signo [femenino] por excelencia, sintagmatiza todos los paradigmas en el espacio de 
los tres mund os y revela los misterios de la tercera edad. De su abrazo nace el protagonista del mundo nuevo, quien es uno y a la vez tres misteriosos jóvenes rubios idénticos entre sí, cada uno con su cruz de sangre roja en la espalda y seis dedos en cada pie. Aparecidos en "El Cabo de los Desastres" en la primera parte del libro, se identifican con el joven náufrago que protagoniza el peregrinaje del descubrimiento en la segunda parte de la novela: la invención de América (pp. 357-494), que es también una simbiosis de verdad y ficción. Es el clímax del camino de aprendizaje del navegante hacia las tierras nuevas y las playas de perlas y oro, y es también el retorno a una memoria olvidada. El peregrino se transfigura en el viejo Pedro, su conductor y acompañante muerto, o toma las formas de Quetzalcóatl y de Huitzilopochtli. Sólo una verdad es cierta: Alguien es siempre Otro que antes ha sido y que volverá a Ser. Ésta es una constante en la semiosis tranformacional de los personajes en la novela.

Sin embargo, hay una diferencia en la caracterización de la identidad en la primera y en la segunda parte del libro. En tanto los protagonistas de "El viejo mundo", por ejemplo Felipe, retienen la identidad original en sus distintas transformaciones, el protagonista descubridor de "El mundo nuevo" posee una identidad huidiza, como memoria perdida y recobrada en los personajes del mundo indígena de la conquista.

—Esto ya lo viví antes... esto ya lo sabía... esto lo vivo por segunda vez... (p. 382)

-Yo, el hombre sin memoria ocupo el lugar del señor de la memoria. Yo, el extraño llegado del mar, soy el fundador. Yo, el desnudo y desposeído soy el joven jefe. Yo, el último de los hombres soy el primer hombre. (p. 408)

- ¿Quién soy?... Eres uno en la memoria. Eres otro en el olvido.

Y la señora añadió:

- Serpiente de plumas en lo que recuerdas. Espejo humeante en lo que no recuerdas. (p. 452)

-Y mi doble oscuro, desnudo... a todos les dijo que yo era, en verdad, la Serpiente Emplumada, el gran sacerd ote del origen del tiempo, el creador de los hombres, el dios de la paz y del trabajo...; éste es en verdad el llamado Quetzalcóatl, el dios blanco, enemigo de los sacrificios. (p. 464)

El náufrago del mundo nuevo al verse a sí mismo en el retorno de un tiempo olvidado debe emprender la conquista de su propia identidad. Aún en la tercera parte de la novela, el náufrago fundador, el primer hombre, reaparece en "la última ciudad" como protagonista enmascarado en la persona de un $t u ́$, conductor de la memoria de otro tiempo que el yo ha olvidado. El personaje se transfiere en lector, narrador y protagonista de su propia crónica: "Te cansas pronto de leer. Nunca sabes si entristecerte o alegrarte de que estos papeles, estas mudas voces de hombres de otros tiempos, sobrevivan a las muertes de 
los hombres de tu tiempo. ¿Para qué conservas los escritos? Nadie los leerá porque ya no habrá nadie para leer, escribir, amar, soñar, herir, desear". (p. 768)

"La última ciudad" restituye su sincronía a todos los personajes de todos los espacios y todos los tiempos, en un solo espacio: París, y en un solo tiempo: el último día de un siglo agónico. La noche última de 1999 es el fin y el principio, con presagio de apocalipsis y de nuevo génesis. Los personajes más significativos de la literatura hispanoamericana de las décadas del 60 y 70 (Oliveira, Buendía, Cuba Venegas, Pierre Ménard, el Mudito, Zavalita) protagonizan la espera del año 2000.

Decía [Cuba Venegas], ignorando la paráfrasis:

- Todos los buenos latinoamericanos vienen a morir a París.

Quizás tenía razón. Quizás París era el punto exacto del equilibrio moral, sexual e intelectual entre los dos mundos que nos desgarraron: el germánico y el mediterráneo, el norte y el sur, el anglosajón y el latino. (pp. 765-766)

París es el espacio como utopía, signo único y múltiple, como el Aleph del mundo, vértice receptor de todos los reflejos donde confluye el principio y fin de la novela.

Es evidente que esta permutación de signos distantes que se recuperan y se pierden en otros signos confiere al texto el proceso de una productividad nunca acabada, lo que quiere decir que su relación con la lengua está en una operación destructiva-constructiva. La organización textual en Terra Nostra emerge de una práctica semiótica dada por la inserción de textos dentro del texto, como espacio donde se neutralizan múltiples enunciados de distinta procedencia.

En el proceso narrativo de Terra Nostra, la historia asume una función semiótica como operación espacio-temporal. Pero no se ha de pensar en la historia en abstracto, sino en la forma en que Fuentes, autor y compilador, lee la historia. La verdadera función del facto histórico, según Fuentes, reside en la capacidad de repetirse-perderse-volver a ser. Esta alternancia disyuntiva de memoria-olvido permite que cada signo histórico (diacrónico) reiterado cíclicamente se re-inscriba en la sincronía de otro contexto. El volver a ser implica un cambio: ser el mismo y ser distinto.

Esta lectura de la historia tiene su apoyo en la historiografía moderna. Benedetto Croce, a principios del siglo, como un desafío a la pretendida autonomía de los hechos de la historia, afirma: "Toda verdadera historia es contemporánea", ${ }^{4}$ lo que indica que la historia consiste en ver el pasado desde

\footnotetext{
2 Benedetto Croce, History, Theory and Practice (New York: Russell \& Russell, 1960), p. 12; trad. de la primera edición italiana, de 1916. La traducción al español es mía.
} 
el contexto del presente. También R. G. Collingwood en The Idea of History (1946) señala que "la filosofía de la historia no se ocupa solamente del pasado en sí ni de la opinión que de él tiene el historiador, sino de ambos relacionados." "El pasado que estudia el historiador no es muerto, sino un pasado que en cierto modo vive en el presente". ${ }^{5}$ La reconstitución del pasado no sólo consiste en enumerar hechos, lo importante es la interpretación y selección de éstos, lo que precisamente los hace históricos. Como confirma el medievalista G. Barraclough en History in a Changing World (1955), "la historia que leemos aunque basada en los hechos no es, en puridad, en absoluto, fáctica, sino más bien una serie de juicios admitidos". ${ }^{6}$

Esta crítica aguda que al mismo tiempo ofrece sus reservas, pues puede significar un arma de doble filo, evidencia sin embargo, que la historia nunca puede ser completamente objetiva. El historiador Edward Carr en What is History (1961) se pregunta "¿Qué es un hecho histórico?" A veces un dato al pie de página, una nota que es luego tex to y pasa a ser al cabo de un tiempo un facto histórico arraigado. Puede ser asimismo que nadie vuelva a mencionar el hecho y éste desaparezca entre los acontecimientos no históricos. "La movediza barrera que separa los hechos históricos de los que no lo son se esfuma porque los pocos hechos conocidos son todos ellos históricos". 7 Los hechos históricos son los marcados; los no marcados son los olvidados. Los hechos no son históricos, se los hace históricos. Por consiguiente, toda inquisición en la posibilidad de la historia implicaría su propia imposibilidad. En cuanto la historia encarna en la palabra y en la escritura de un sujeto, deja de ser facto histórico, en abstracto, para ser discurso. La historia no puede desprenderse del proceso cultural humano y es prueba de la insuficiencia humana. Es éste el sentido que mueve la semiótica de la historia en Terra Nostra, en un constante proceso de descodificación y re-codificación del signo histórico, que emerge en la alternancia de un epistema disyuntivo: pérdida/ recuperación.

La alternancia del signo histórico corporiza en la narrativa como: (1) facto temporal; (2) espacio institucional; (3) personaje o transfigura reiterada en recurrencia cíclica; (4) texto-escritura (artefacto). Como facto, en Terra Nostra hay tres fechas implacables: 1492, el descubrimiento de América; 1521, la conquista de Tenochtitlán; 1598, la muerte de Felipe II, testigo del

\footnotetext{
${ }^{5}$ B. C. Collingwood, Introducción a su The Idea of History (Oxford: Oxford University Press, 1946).

- Barraclough, History in a Changing World, citado por E. H. Carr, en Qué es historia (Barcelona: Seix Barral, 1969), p. 19; trad. de What is History (London: 1961).

${ }^{7}$ E. H. Carr, Qué es historia, pp. 21-37.
} 
nacimiento de América y del comienzo de la decadencia de España. Estas fechas son trazos que se re-leen y se re-escriben: "La historia fue la misma: tragedia entonces y farsa ahora, farsa primero y tragedia después, ... todo fue una mentira, se repitieron los mismos crímenes, los mismos errores, las mismas omisiones que en otra cualquiera de las fechas verídicas de la cronología lineal, implacable, agotable: 1492, 1521, 1598" (p. 779). Las tres fechas claves son los trazos generadores de los factos históricos futuros. Paralelamente, tres espacios heterosémicos, Lepanto, Veracruz, el Cabo de los Desastres (p. 778) son generadores del vacío de un nuevo espacio excéntrico: América, Terra Nostra, frente al Mare Nostrum. El espacio geográfico sincroniza el hecho temporal y le confiere potencialidad de reiteración. El espacio ta mbién se instituye como permanencia en la piedra, en el monumento ideológico: El Escorial-El Valle de los Caídos; La Iglesia o Convento-La Pirámide o Piedra de Sacrificios. Los personajes son las transfiguras, máscaras de infinitos rostros, mediadoras de vacío de identidades des-personalizadas que confluirán en la noche-también histórica-del 31 de diciembre de 1999, en el espacio también utópico de París. La escritura de Terra Nostra es texto bíblico en el sentido de que es libro de libros. El que escribe es el lector del texto que transcribe. La lectura es productora de la escritura en producción. Por lo tanto, estudiar a Terra Nostra como texto, es seguir el proceso escriptural de un sistema semiótico que incorpora rasgos de otros textos, sea re-copiados, o re-creados como huellas de la memoria. Julia Kristeva llama "productividad" al nivel de la actuación textual, en la intertextualidad, es decir, en el cruce de la modificación recíproca de unidades pertenecientes a diacronías de textos distintos. ${ }^{8} \mathrm{El}$ paradigma generador es el geno-texto o competencia, acervo pre-existente que se inserta en el nuevo texto, o sea el feno-texto, descodificador que corporiza la actuación y el proceso transformacional del sistema.

En la competencia generadora de Terra Nostra habrá que considerar (1) los textos anteriores de Fuentes, Los dias enmascarados, Las buenas conciencias, La muerte de Artemio Cruz y, especialmente, Aura, sin descontar otros no mencionados; (2) los textos de la historia y la literatura europea, especialmente de la España medieval y renacentista re-escritos en "El viejo mundo"; (3) las crónicas de la conquista española en América y otros tex tos históricos y literarios del mundo nuevo; (4) los textos de la historia y el pensamiento filosófico contemporáneo. De toda esta vastísima competencia estructural, son las obras anteriores del mismo Fuentes y los textos históricos, los que más singularmente organizan el discurso original de Terra Nostra. Entre los textos de Fuentes, Aura es la escritura germen. Su protagonista, Felipe, historiador y

8 Julia Kristeva, El texto de la novela (Barcelona: Lumen, 1970), pp. 90; 98-9. 
creador, es el tú conducido por una memoria ausente que prefigura el texto de Terra Nostra: “. . . podrías pasar cerca de un año dedicado a tu propia obra; tu gran obra de conjunto sobre los descubrimientos y conquistas españolas de América, una obra que resuma todas las crónicas dispersas, las haga inteligibles, encuentre las correspondencias entre todas las empresas y aventuras del siglo de oro, entre los prototipos humanos y el hecho mayor del Renacimiento".9 Fuentes bosqueja en el tú de Felipe, el discurso del protagonista "memorioso" de "El otro mundo". El proceso transformacional de los personajes de Aura y su búsqueda del conocimiento olvidado se re-escribe en Terra Nostra. "Volverá" es el verbo que inicia y cierra el discurso de Aura.

Por otra parte, en al análisis de textos históricos, las crónicas de la conquista insertas en "El mundo nuevo" constituyen uno de los procesos de intertextualidad más interesantes y válidos. Por ejemplo, entre las páginas 458-68 de Terra Nostra se detectan, copiados o recreados con aparente arbitrariedad, geno-textos provenientes de las Cartas de relación de Hernán Cortés (pp. 461-62, 463, 465, 466, 467), de la Historia de Tlaxcala de Diego Muñoz Camargo (pp. 458-459, 460, 463, 464, 466) con un notorio predominio, por la extensión de los textos, de la Visión de los vencidos del Códice florentino, según los informantes de Sahagún presentan los presagios anteriores a la conquista. ${ }^{10}$ No es novedad la inclusión de textos históricos en la novela hispanoamericana, pero sí es singular, en el caso de Terra Nostra, la conciencia crítica de la asimilación del discurso histórico como memoria de un conocimiento [ideología] recobrado. En el mecanismo operacional del discurso de Terra Nostra, un geno-enunciado histórico (diacrónico-sincrónico) al sintagmatizarse en un nuevo contexto se descodifica tanto de su unicidad (eje diacrónico) como de su doble función (el binarismo diacroníasincronía), para re-codificarse como intertextualidad entre la voz del narrador y la recepción del destinatario, produciendo un nuevo significado compartido por ambos textos. Esta productividad textual es, en definitiva, un metadiscurso que llamaré heterosémico y clasificaré como espacio-cultural-ideológico, porque se re-inscribe como memoria (cultura) recuperada cíclicamente en un espacio heterosémico. La operación cíclica no ofrece simplemente la

\footnotetext{
${ }^{9}$ Carlos Fuentes, Aura (México: Era, 1962), p. 31.

${ }^{10}$ En uno de los seminarios que he dictado en la universidad de Wisconsin he examinado, con la colaboración de mis estudiantes, las reincidencias de en unciados de las mencionadas crónicas y de otras, en el texto de Terra Nostra, especialmente en "El mund o nuevo". Dadas las limitaciones de extensión de este ensayo, no he de confrontar aquí las citas de dichos textos (Terra Nostra y las crónicas respectivas). Sólo indico unas pocas páginas de Terra Nostra en las cuales es observable esta alquimia lingüística histórico-cultural.
} 
forma de círculo sino de espiral, como alternancia en abierta disyunción, en proceso (memoria-olvido) hacia otra transformación.

Desde un punto de vista teórico-crítico mi propuesta sobre la operación tranformacional del discurso de Terra Nostra confirma el concepto de Yuri Lotman acerca del mecanismo semiótico de la cultura: "la implantación de un facto en la memoria colectiva es como una traducción de un lenguaje a otro-en este caso, lenguaje cultural"--agrego, ideológico. La cultura es básicamente memoria como defensa contra el olvido.

"Yury M. Lotman and B. A. Uspensky, "On the Semiotic Mechanism of Culture", New Literary History, 9, No. 2 (Winter 1978), 214. 